\title{
Ensiklopedisiteit in die Woordeboek van die Afrikaanse Taal: 'n "Saak" van balans*
}

\author{
Willem Botha, Buro van die Woordeboek van die Afrikaanse Taal, \\ Stellenbosch, en Departement Afrikaans en Nederlands, \\ Universiteit Stellenbosch, Stellenbosch, \\ Republiek van Suid-Afrika (wfb@sun.ac.za)
}

Opsomming: Die Woordeboek van die Afrikaanse Taal (voortaan WAT) het vanaf die negende deel wegbeweeg van 'n meer ensiklopediese aanbod van inligting. Hiervoor het die woordeboek heelwat lof van teoretici ontvang. Die mening is egter ook uitgespreek dat die WAT wat leksikografiese funksie betref meer op die kognitiewe funksies, wat veral ensiklopediese inligting behels, moet konsentreer. In reaksie hierop word daar probeer om vas te stel of die WAT vanaf die negende deel ' $n$ balans gevind het tussen ensiklopediese en semantiese inligting. Vir hierdie doel word daar gefokus op Wiegand se sienings rondom die hantering van ensiklopediese inligting in verklarende woordeboeke asook die meer tradisionele beginsel van komponentontleding.

Sleutelwoorde: ENSIKLOPEDIESE INLIGTING, KOGNITIEWE FUNKSIE, KOMMUNIKATIEWE FUNKSIE, KOMPONENTONTLEDING, LEKSIKOGRAFIESE FUNKSIE, POLIFUNKSIONEEL, SEMANTIESE INLIGTING

\begin{abstract}
From the ninth volume, the Woordeboek van die Afrikaanse Taal (henceforth WAT) moved away from a more encyclopaedic presentation of information. Theorists reacted positively to this change of direction. The opinion was, however, also expressed that the WAT, as far as lexicographic function is concerned, should concentrate more on cognitive functions, which include especially encyclopaedic information. In response to this opinion, an effort is made to establish whether the WAT has from volume nine succeeded in finding a balance between encyclopaedic and semantic information. For this purpose the focus is on Wiegand's views on the presentation of encyclopaedic information in explanatory dictionaries as well as the more traditional principle of component analysis.
\end{abstract}

Keywords: COGNITIVE FUNCTION, COMMUNICATIVE FUNCTION, COMPONENT ANALYSIS, ENCYCLOPAEDIC INFORMATION, LEXICOGRAPHIC FUNCTION, POLIFUNCTIONAL, SEMANTIC INFORMATION

\footnotetext{
* Hierdie artikel is 'n verwerking van 'n hoofstuk uit 'n D.Litt.-proefskrif Die impak van die leksikografieteorie op die samestelling van die Woordeboek van die Afrikaanse Taal, wat in April 2003 deur die Universiteit Stellenbosch, Stellenbosch, Republiek van Suid-Afrika, aanvaar is.
} 


\section{Inleiding}

Die eerste ag dele van die Woordeboek van die Afrikaanse Taal (voortaan WAT) is hewig gekritiseer vanweë die ensiklopediese aanbod van inligting in hierdie dele. Die WAT het egter op hierdie kritiek ag geslaan en vanaf Deel IX is daar nie weer na die ensiklopediese aard van artikels verwys nie, maar is die algemene bondigheid waarmee inligting aangebied word, aangeprys. Na aanleiding van 'n verrassende stelling van Feinauer (2007) dat die WAT meer op die kognitiewe (wat veral ensiklopediese en etimologiese inligting behels) moet konsentreer, word daar in hierdie artikel probeer om die mate van ensiklopedisiteit in dele IX tot XII van die WAT vas te stel.

\section{Kritiek op die ensiklopediese element in die WAT}

\section{$2.1 \quad$ WAT I tot VI}

Uit 'n ondersoek na die kritiek op die eerste ses dele van die WAT blyk dit dat die kritiek teen die ensiklopediese betekenisverklarings progressief feller geword het totdat dit met die verskyning van Deel VI 'n hoogtepunt bereik het (Botha: 2003: 83).

Die resensente is dit eens dat die aanbieding van saakbeskrywing in plaas van betekenisbeskrywing, die oorsaak van die WAT se ensiklopediese definisies is. Snijman (1995a: 210-211) erken dat ekstra-linguistiese faktore by die redaksie ' $n$ rol speel in die bepaling van die hoeveelheid saakkenmerke wat vermeld word, en dat verbesondering oordryf kan word. Hy verstrek egter ook insiggewende motivering vir die insluiting van skynbaar oortollige saakkenmerke by 'n simpleks, soos dat die saakkenmerke noodsaaklik is vir begrip van sommige samestellings of uitdrukkings waarin dit voorkom.

Snijman (1995a: 205-206) sluit hom aan by Zgusta (1971: 41) se beskouing dat daar dikwels 'n ooreenstemming is tussen die toepassingsveld van ' $n$ woord en die kenmerkende eienskappe van die saak wat deur die woord benoem word.

Schoonees (1952: 289), hoofredakteur van Deel I tot IV, sê onder meer dat die redaksie "soveel as moontlik probeer gee het". Dit het "van Taalkundiges die verwyt van ensiklopedisiteit gebring, van die kant van die praktiese gebruiker egter nog slegs ingenomenheid en aanmoediging - en dit tel ook!" Ook elders verklaar Schoonees (1958: 81-83) dat die WAT probeer gee wat die gebruikers verlang en as die woordeboek daardeur ensiklopedies word, "dan wil ons graag ensiklopedies wees". Schoonees (1957: 122) konstateer ook dat sekere woorde feitlik "ensiklopediese besonderhede vereis" om presies begryp en gehanteer te kan word. Dié woorde "is ryk aan individuele onderskeidinge, soos kenmerke, en arm aan algemene onderskeidinge ... Woorde wat sulke dinge benoem, (is) gebind aan die dinge met hulle individuele onderskeidinge ... As die omskrywing presies wil wees, moet dit ook met die benoemde saak 
self rekening hou." Met laasgenoemde twee stellings nader hy 'n teoretiese fundering van die ensiklopediese element in die WAT, maar die bevrediging van die behoeftes van die gebruiker bly sy primêre motivering vir die insluiting van ensiklopediese elemente.

Terwyl dit vir Schoonees om die behoeftes van die gebruiker gegaan het en hy die ensiklopediese op hierdie basis geregverdig het, het Snijman (1995a, 1995b, 1995c, 1995d) die ensiklopediese werkwyse van die WAT deurgaans teoreties probeer verantwoord. Hierin het hy egter konsekwent 'n teenoorgestelde standpunt ingeneem as die teoretici wat die kritiek uitgespreek het. So gebruik Eksteen (1968) Reichling se uitgangspunte om die werkwyse van die WAT te kritiseer terwyl Snijman (1995b) dit gebruik om die werkwyse te motiveer. In onlangse metaleksikografiese gesprekke word aangesluit by Snijman se standpunt dat die ensiklopediese in verklarende woordeboeke nie net benader kan word uit 'n blote kontrasstelling tussen leksikale betekenis en saak nie. Tarp (2000: 190) redeneer dat dit by 'n bespreking van kwessies soos saakbeskrywing en betekenisbeskrywing eerstens moet gaan oor die funksie van die spesifieke woordeboek en die bevrediging van die behoeftes van die gebruiker. Die pragmatiese moet dus voorop gestel word, maar dit moet terselfdertyd deur die teorie gelei word. Volgens Swanepoel (1995: 209) slaag Snijman daarin om verskeie van die kompleksiteite van die linguisties-teoretiese kwessies en die talle leksikografies-pragmatiese faktore wat by die ensiklopediese op die spel is, na vore te bring.

Alhoewel Snijman (1977: 17; 1995d: 185) na aanleiding van die kritiek op die ensiklopediese element in Deel VI verskeie praktiese oplossings voorgestel het, was dit duidelik dat hy nie ten gunste was van ingrypende veranderinge wat die eenheidskarakter van die WAT kon skend nie. Hierin is 'n mate van ironie aanwesig, aangesien die ensiklopediese karakter van Deel I geensins die afmetings aanneem van dié van Deel VI nie.

\subsection{WAT VII tot VIII}

Kritici is dit eens dat ten spyte van die WAT se poging om die ensiklopediese element te beperk, dele VII en VIII steeds gekenmerk word deur saakbeskrywing eerder as betekenisbeskrywing (Botha 2003: 107).

Volgens Gouws (1985 en 1992), Feinauer (1993), Raidt (1993) en Botha (1984) is daar ' $n$ merkbare verbetering in deel VII en veral deel VIII ten opsigte van die ensiklopediese, maar is daar nog steeds gevalle waar gebruiks- en saakbeskrywing as betekenisbeskrywing aangebied word.

\subsection{Herontwerpte WAT vanaf deel IX}

Dit wil voorkom asof ensiklopedisiteit as verskynsel vanaf Deel IX finaal besweer is. Geen resensent noem ensiklopedisiteit as 'n negatiewe punt van kritiek teen enige van die dele vanaf WAT IX nie. 
Volgens Gouws (1994) bewys WAT IX dat die redaksie op die kritiek ten opsigte van die ensiklopediese ag geslaan het. Oor die algemeen is die betekenisverklarings syns insiens nie net bondiger as vroeër nie, maar dit bevat ook baie minder ensiklopediese inligting. In hierdie opsig vertoon WAT IX baie beter as sy voorgangers.

In sy resensie van Deel X wys Gouws (1996) weer eens daarop dat die weergawe van 'n oormatige hoeveelheid ensiklopediese inligting ' $n$ tradisionele punt van kritiek teen die WAT was. Hy konstateer voorts dat hierdie probleem in Deel $X$ opgelos is en dat die artikels 'n deeglike betekenisomskrywing van die lemma bied. Hy maak egter die terloopse opmerking dat "die verbetering so ver gevoer (is) dat ' $n$ mens soms selfs voel dat ' $n$ bietjie meer inligting van waarde sou gewees het".

In 'n resensieartikel van WAT XII lewer Feinauer (2007: 269-270) 'n pleidooi vir meer ensiklopediese inligting in die WAT-definisies. Hiermee het die kritiek rondom ensiklopedisiteit in die WAT die kringloop voltooi: vanaf 'n hewige veroordeling van die ensiklopedisiteit na 'n aanprysing van die bondige definisies met deeglike betekenisbeskrywing sonder ' $n$ oormaat ensiklopediese inligting en ' $n$ uiteindelike pleidooi vir 'n meer ensiklopediese benadering.

Feinauer (2007) beroep haar op Bergenholz en Tarp (2003: 176) wat 'n onderskeid tref tussen die kognitiewe en kommunikatiewe funksies van 'n woordeboek. Die behoefte van die gebruiker bepaal watter van hierdie funksies die sterkste in 'n bepaalde woordeboek behoort te figureer. Die kognitiewe of kennisgerigte funksies behels veral ensiklopediese en etimologiese inligting, spesifieke inligting oor die register of vakgebied van die lemma en grammatikale inligting. Een van die tipiese kommunikatiewe funksies is uitspraakleiding. Volgens Feinauer (2007) is die hooffunksie van die WAT as omvattende woordeboek waarskynlik meer kognitief as kommunikatief. Die WAT moet derhalwe meer op ensiklopediese en etimologiese inligting gerig wees as op byvoorbeeld uitspraakleiding. Vir laasgenoemde moet die gebruiker eerder standaard verklarende woordeboeke, aanleerderwoordeboeke of vertalende woordeboeke raadpleeg.

In teenstelling met bostaande standpunt van Feinauer dat die WAT meer kognitief as kommunikatief behoort te wees, kan dit waarskynlik eerder gekonstateer word dat 'n omvattende woordeboek soos die WAT nie kan kies om meer kognitief of kommunikatief te wees nie, maar moet probeer om op gebalanseerde wyse alle funksies te omvat. Uit die oogpunt van leksikografiese funksies behoort die WAT dus op gebalanseerde wyse polifunksioneel te wees. Feinauer (2009) kom dan ook tot die slotsom dat haar standpunt ten opsigte van die ensiklopediese eerder op kritiek op die oordadige aanbod van uitspraakleiding neerkom. Soms word meer as ses verskillende uitspraakmoontlikhede aangebied wat die indruk van 'n kommunikatiewe eerder as ' $n$ kognitiewe of gebalanseerde benadering wek.

Ongelukkig word daar nie in die betrokke resensieartikel van Deel XII 'n analise van spesifieke betekenisverklarings gemaak om vas te stel of genoeg, te 
min of te veel ensiklopediese inligting volgens die behoefte van die teikengebruiker verskaf word nie. Daar sal voorts probeer word om volgens die model van Wiegand vas te stel wat die stand van ensiklopedisiteit in die nuwe dele van die WAT vanaf WAT IX is.

\section{Wiegand se model vir 'n balans tussen semantiese en ensiklopediese inligting in betekenisbeskrywing}

In hierdie gedeelte sal daar gefokus word op Wiegand se sienings rondom die hantering van ensiklopediese inligting in verklarende woordeboeke en sal dit ook teenoor die meer tradisionele beginsel van komponentontleding gestel word.

Wiegand (1984: 21-22 en 1994: 267-271) stel nie 'n absolute grens tussen betekenis- en saakbeskrywing nie. Volgens Wiegand kan 'n leksikografiese definisie ("lexical paraphrase"/"meaning paraphrase") altyd óf as betekenisbeskrywing óf as saakbeskrywing geïnterpreteer word. Indien dit as betekenisbeskrywing gesien word, karakteriseer die definisie steeds terselfdertyd die saak, en indien dit as saakbeskrywing gesien word, is dit steeds terselfdertyd 'n verklaring van die betekenis van die lemma. Daar is derhalwe 'n mate van oorvleueling tussen ensiklopediese inligting en semantiese inligting wat Wiegand ensiklopediese saakbeskrywende betekeniskennis ("encyclopaedic object-constituting meaning knowledge") noem. Gouws (1989: 186) sluit in 'n sekere sin by hierdie uitspraak aan wanneer hy konstateer dat 'n mate van ensiklopedisiteit in enige verklarende woordeboek onvermydelik is.

Volgens Wiegand (1994: 268) is die saakbeskrywende betekeniskennis daardie deel van die semantiese kennis wat as 'n kenmerkende deel van die ensiklopediese kennis beskou kan word. Hierdie kennis word daardeur gekenmerk dat dit gemeenskaplike kennis by die meerderheid van die sprekers is. In die onderstaande skets uit Wiegand (1994: 268) word aangetoon dat die ensiklopediese betekeniskennis uit kennis van stereotipes (that lemons are yellow/ juicy) en kennis van kategorieë (that a lemon is a fruit/food) bestaan. Veral die kennis van stereotipes kan nie duidelik van ensiklopediese feitekennis onderskei word nie.

Onderstaande uiteensetting hou verband met die niegespesialiseerde woordeskat van 'n taal (Wiegand 1994: 269). Dit is die resultaat van 'n vraelys met 21 kenmerke van 'n suurlemoen wat aan 100 studente voorgelê is met die opdrag om aan te dui wat hulle as die belangrikste kenmerke beskou. Wiegand (1984: 27) stel dit duidelik dat hy nie van leksikograwe verwag om soortgelyke proefnemings te onderneem ten einde die gehalte van hul "lexical/meaning paraphrases" te verbeter nie. Die doel van die proefneming is eerder om aan te dui hoe die "byt" uit die vraag watter kenmerke in 'n betekenisparafrase opgeneem behoort te word, gehaal kan word. Eerstens moet die betekenisverklaring as 'n integrerende deel van die woordeboekartikel gesien word, en nie as 'n geïsoleerde entiteit nie. 


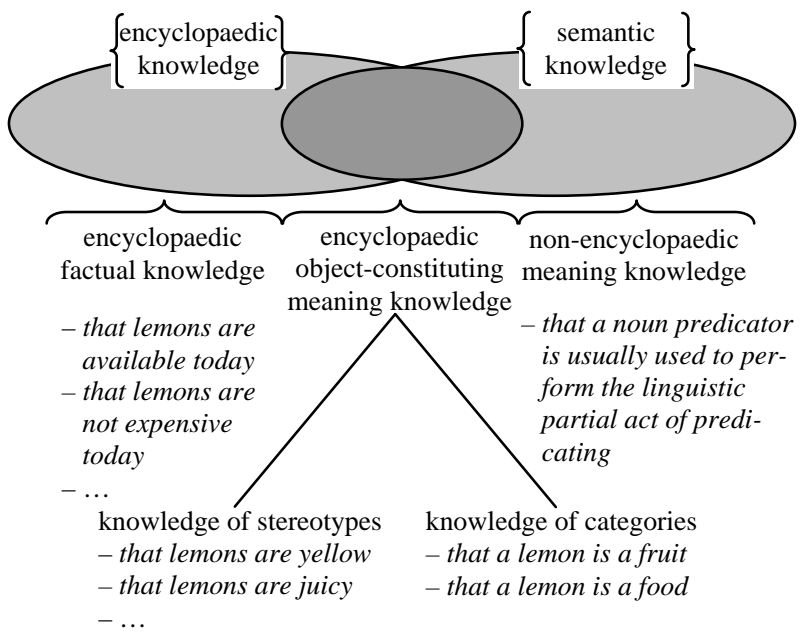

Wiegand (1984: 27) sien die woordeboekartikel as 'n teks bestaande uit linguistiese voorligting waarmee die leksikograaf die woordeboekgebruiker voorlig oor die gebruik van 'n gelemmatiseerde leksikale item. Nie slegs die betekenisverklaring nie, maar ook ander tekselemente help om die betekenis van die lemma aan die gebruiker te verduidelik. Volgens Wiegand (1984: 27-28) is dit geen uitgemaakte saak dat die betekenis van 'n leksikale item die beste verstaan word deur na die sg. belangrikste kenmerke te verwys nie. Derhalwe moet ander relatief belangrike kenmerke ook in die woordeboekartikel in berekening gebring word. Sy voorstel is dat 'n leksikografiese voorbeeldsin geformuleer word waarin van die ander eienskappe figureer.

Met hierdie model wil Wiegand die begrip van 'n definisie wat op akademiese en wetenskaplike gebruik gebaseer is, vervang met ' $n$ benadering wat ingestel is op algemene gebruik en die behoeftes van die teikengebruikers van 'n woordeboek, en wat derhalwe van woordeboek tot woordeboek aangepas kan word.

Volgens Wiegand (1994) kan 'n genus-differentia-definisie wat gebaseer is op 'n komponentontleding, nie die denotatiewe betekenis van 'n leksikale item toereikend weerspieël nie. Die gebruiker het meer kennis nodig om die leksikale item doeltreffend in die regte kontekste en volgens die gewone reëls in die omgangstaal te kan gebruik. Die leksikograaf moet die behoeftes van die gebruiker ken en die betekenisverklaring daarvolgens saamstel (Wiegand 1994: 265). Derhalwe sal die betekenisverklarings van leksikale items wat na sake verwys wat só vreemd aan die verwagte teikengebruiker is dat hy meer ensiklopediese kennis benodig ten einde dit uit te ken, geformuleer word om ensiklopediese feitekennis oor te dra. Alternatiewelik kan die ensiklopediese inligting wat buite die oorvleueling van die ensiklopediese en semantiese inligting val, ook deur die voorbeeldmateriaal of deur ander metaleksikografiese metodes oorgedra word ten einde die ongekontroleerde en oorbodige aanbod daar- 
van in die betekenisbeskrywing teen te werk. Wiegand (1994: 271) is van mening dat taksonomiese name onder andere nie in 'n betekenisverklaring hoort nie. Die voorstel om ensiklopediese inligting ook deur middel van ander inligtingstipes as die betekenisverklaring te verskaf, sluit aan by Wiegand se model van die woordeboekartikel as 'n geïntegreerde teks.

Ten einde vas te stel of die WAT-artikels die gewenste balans tussen semantiese en ensiklopediese inligting volgens Wiegand se model handhaaf om die gebruiker in staat te stel om die lemma doeltreffend in normale taalgebruik aan te wend, sal enkele artikels uit Dele IX, X, XI en XII beskou word. Ter vergelyking sal die meer tradisionele metode van komponentontleding ook op dieselfde WAT-artikels toegepas word.

Die patroon waarvolgens lemoen in die WAT beskryf word, toon 'n groot ooreenkoms met die betekenisbeskrywing wat Wiegand (1984: 27) vir lemon formuleer:

lemon ... oval fruit of the lemon tree with juicy, sour pulp and yellow rind

lemoen ... 1 Vrug v.d. lemoenboom (LEMOENBOOM 1), met 'n oranje skil en soeterige sap wanneer dit ryp is

Beide betekenisverklarings gee "knowledge of categories" weer deur die saak waarna die definiendum verwys, as 'n vrug te beskryf. Beide gee "knowledge of stereotypes" weer deur kenmerke ten opsigte van kleur, inhoud en smaak te noem. Wiegand beskryf ook die vorm ("oval") terwyl die WAT-betekenisverklaring die kwalifikasie bevat dat die genoemde kenmerke manifesteer wanneer die lemoen ryp is.

Wiegand se "knowledge of categories" en "knowledge of stereotypes" toon ooreenstemming met die onderskeiding tussen gemeenskaplike en diagnostiese komponente by komponentontleding. Gemeenskaplike komponente plaas die lemma in die semantiese veld waartoe hy behoort deurdat 'n baie algemene betekeniskenmerk gespesifiseer word. Diagnostiese komponente is 'n weergawe van betekeniskenmerke wat daarop gemik is om die lemma van ander lede van dieselfde semantiese klas te onderskei (Gouws 1989: 190). Gouws wys daarop dat die gebruik van gemeenskaplike en diagnostiese komponente 'n regstreekse verband met die gebruik van genus-differentia-definisies vertoon. Die gemeenskaplike en diagnostiese komponente word as onderskeidelik die genus en die differentia in die definiens aangebied.

Uit die oogpunt van komponentontleding kan die kwalifikasie "wanneer dit ryp is" as 'n supplementêre komponent beskou word. Dit het nie betekenisonderskeidende waarde nie en is nie-noodsaaklike inligting wat neig na ensiklopediese feitekennis of saakbeskrywing.

Wiegand (1984: 28) sluit die rypheidskwalifikasie in onder die minder kenmerkende "stereotypes" wat in 'n leksikografiese voorbeeld (poëem) vervat is, nl.:

The lemon, which is a type of citrus fruit, has a thick rind and is green when unripe 
In die WAT-artikel word soortgelyke ensiklopediese saakbeskrywende betekenisinligting ("encyclopaedic object-constituting meaning knowledge") in die voorbeeldmateriaal weergegee, soos dat die lemoen 'n sitrusvrug is, vitamien $C$ bevat, afgeskil word en uit skyfies bestaan:

Vitamien C wat veral in koejawels, lemoene en ander sitrussoorte voorkom (P.C.J. Kuun: Mod. Landb. Vorm I2, 1967, 146). 'n Vrou (sit) ... en aankyk hoe kinders ... lemoene afskil, skyfies daarvan onder mekaar verdeel en smaaklik eet (L. Maré: Lemoene, 1931, 6).

Samevattend kan verklaar word dat uit die oogpunt van komponentontleding die WAT-betekenisbeskrywing van lemoen in 'n baie geringe mate inligting bevat wat neig na die ensiklopediese. Ooreenkomstig Wiegand se model kan die inligting vervat in die frase "wanneer dit ryp is" net so goed deur 'n ander inligtingstipe, soos die voorbeeldmateriaal, weergegee word. Andersins stem die WAT-artikel in 'n baie hoë mate ooreen met die Wiegand-model.

'n Relevante vraag, in teenstelling met die vraag hoe vasgestel word of ' $n$ betekenisverklaring te veel ensiklopediese betekenisinligting bevat, is hoe bepaal word of ' $n$ verklaring genoeg ensiklopediese betekenisinligting bevat ten einde die gebruiker in staat te stel om die leksikale item te gebruik of om die saak waarna verwys word, uit te ken. Lessenaar word soos volg omskryf:

Tafel ontwerp vir skryf en studeer

Volgens beide Wiegand se model en komponentontleding is dit duidelik dat hier nie sprake van suiwer ensiklopediese feitekennis in die betekenisverklaring is nie. Tafel vorm die gemeenskaplike komponent, genus of "knowledge of categories" in die beskrywing, terwyl ontwerp vir skryf en (ontwerp vir) studeer die diagnostiese komponente, "knowledge of stereotypes" of differentiae vorm.

Uit die sitate kan die gebruiker egter ensiklopediese inligting herwin, soos dat 'n lessenaar laaie kan hê:

Daar is altesaam ag laaitjies in die lessenaar om die orde te help handhaaf (Boerd. S.A., Sept. 1971, 86).

In die geval van lessenaar word die minimum "encyclopaedic object-constituting meaning knowledge" weergegee, maar kan daar, soos Wiegand inderdaad bepleit, ensiklopediese inligting uit die voorbeeldmateriaal geabstraheer word. Of die inligting voldoende is vir die gebruiker om die lemma doeltreffend in die regte kontekste en volgens die gewone reëls in die omgangstaal aan te wend, sal afhang van die bepaalde gebruiker se behoeftes. As die WAT se teikengebruiker, nl. "alle sprekers en gebruikers van Afrikaans, maar veral dié spektrum gebruikers wat strek van senior hoërskoolleerlinge tot Afrikaansakademici" egter in gedagte gehou word, behoort die inligting wel toereikend te wees met die oog op doeltreffende kommunikasie.

Sommige items met 'n hoë gebruiksfrekwensie uit die niegespesialiseerde 
woordeskat het soms ook 'n gespesialiseerde betekenis as deel van die gespesialiseerde woordeskat van ' $n$ taal. Wiegand is van mening dat 'n betekenisomskrywing ook vir hierdie "uitbreiding" of ensiklopediese aspekte voorsiening moet maak. Die woordeboekgebruiker sal nie die item korrek kan gebruik indien hy nie oor die nodige ensiklopediese feitekennis beskik nie. Die artikel van olie kan as illustrasie dien:

1 olie ...

I s.nw.

1 a 'n Kleurlose tot swart vloeibare koolwaterstofverbinding met 'n donkerbruin of groenerige skynsel, wat in 'n natuurlike toestand i.d. aardkors voorkom, gew. uit boorgate verkry word, en waaruit verskeie ontvlambare brandstowwe, petrochemikalieë en smeermiddels d.m.v. distillerings- of raffineringsprosesse verkry word; sin. petroleum, ruolie; aardolie (minder gebruiklik), rotsolie (ongewoon), steenolie (ongewoon).

b 'n Ontvlambare vloeistof wat veral verkry word deur olie (10LIE I 1 a) te distilleer of te raffineer, oplosbaar in alkohol en eter, maar onoplosbaar in water is, 'n hoë viskositeit besit, en hfs. as brandstof vir aandrywing, verligting of verhitting, en as smeermiddel gebruik word.

In niegespesialiseerde gebruik kan die betekenisonderskeidings van olie waarskynlik verskraal word tot onderskeidelik "donker vloeistof wat uit die aarde verkry word en waaruit veral brandstof vervaardig word" en "verwerkte olie ('OLIE I 1 a) wat as brandstof en smeermiddel gebruik word". Uit die oogpunt van komponentontleding kan alle bykomende inligting waarskynlik as supplementêre komponente of ensiklopediese inligting beskou word.

Ooreenkomstig Wiegand se model kan geredeneer word dat die leksikograaf die behoeftes van die gebruiker in ag moet neem en die betekenisverklaring daarvolgens moet saamstel (Wiegand 1994: 265). Derhalwe moet die relatief gesofistikeerde gebruiker van 'n omvattende woordeboek soos die WAT van genoeg feitekennis voorsien word ten einde 'n gedetailleerde begrip te verkry van die saak waarna die leksikale item verwys. Gevolglik sou die aangehaalde WAT-betekenisomskrywings van olie as voldoende en as sonder 'n oorbodige aanbod van ensiklopediese feitekennis beskryf kan word.

Petrol is op dieselfde wyse as olie hanteer:

petrol s.nw. ...

1 Vlugtige, ontvlambare vloeistofmengsel van koolwaterstowwe wat deur distillasie uit petroleum, deur kraking van mineraalolie, deur die samepersing van aardgas of die sintese van watergas uit steenkool verkry word, en wat veral as brandstof vir binnebrandenjins, as 'n oplosmiddel, 'n verligtingsmiddel of 'n verdunningsmiddel gebruik word; soms sin. met brandstof en petrolbrandstof (minder gebruiklik).

Dieselfde argumente sou mutatis mutandis kan geld vir die betekenisbeskrywing van Manicheïsme, 'n item wat in 'n hoë mate vreemd aan die gebruikers van die WAT behoort te wees, nl.: 
Manicheïsme ... (na Manes, Persiese wysgeer) Sinkretistiese geestelik-filosofiese leerstelling wyd aangehang i.d. derde en vierde eeu n.C. i.d. Romeinse Ryk, wat voorhou dat daar ' $n$ kosmiese konflik bestaan tussen lig en duisternis, en wat leer dat dit die mens se plig is om die magte v.d. goeie te bevorder, veral deur die beoefening van asketisme en die onthouding van sinlike en materiële genot.

Uit die voorafgaande blyk dit dat indien die WAT-betekenisbeskrywings van leksikale items uit die niegespesialiseerde woordeskat getoets word aan die metode van komponentontleding, daar weinig of geen saakbeskrywing verskaf word nie. In die geval van items uit die gespesialiseerde woordeskat of items wat na sake verwys wat in 'n hoë mate vreemd aan die gemiddelde gebruiker is, kan daar wel 'n ensiklopediese element onderskei word. Hier moet dit egter ook in gedagte gehou word dat 'n mate van ensiklopedisiteit onvermydelik is in enige verklarende woordeboek (Gouws 1989: 186). Gemeet uit die oogpunt van Wiegand se model waarvolgens daar 'n oorvleueling is van ensiklopediese en semantiese betekenis by items uit die niegespesialiseerde woordeskat, en waarvolgens ensiklopediese inligting vereis word by items uit die gespesialiseerde woordeskat en items wat na "vreemde" sake verwys, is die gegewe ensiklopediese inligting in die WAT-betekenisbeskrywings noodsaaklik.

\section{Slot}

In hierdie artikel is daar probeer om op objektiewe wyse vas te stel of die WAT vanaf Deel IX 'n balans tussen semantiese en ensiklopediese inligting handhaaf. Uit die toepassing van die metode van komponentontleding en ook Wiegand se model op enkele artikels sou die gevolgtrekking gemaak kon word dat sodanige balans wel aanwesig is. By implikasie is die gebruiker se behoeftes dus in gedagte gehou by die skryf van die artikels. Die redaksie moet dus voortgaan om hom by die samestelling van die woordeboek te laat lei deur die vraag of die gebruikers van genoeg semantiese en ensiklopediese inligting voorsien word om aan hulle behoeftes te voldoen.

\section{Bibliografie}

Bergenholz, Henning en Sven Tarp. 2003. Two Opposing Theories: On H.E. Wiegand's Recent Discovery of Lexicographic Functions. Hermes. Journal of Linguistics 31: 171-196.

Botha, W.J. 1984. WAT Deel VII. Buurman 15(2): 33 en 35.

Botha, W.F. 2003. Die impak van die leksikografieteorie op die samestelling van die Woordeboek van die Afrikaanse Taal. Ongepubliseerde D.Litt.-proefskrif. Stellenbosch: Universiteit van Stellenbosch.

Eksteen, L.C. 1968. Ensiklopediese beskrywing in die leksikografie. Tydskrif vir Geesteswetenskappe 8(3-4): 236-249. 
Feinauer, I. 1993. Die agste deel van die Woordeboek van die Afrikaanse Taal. Tydskrif vir Geesteswetenskappe 33(4): 286-298.

Feinauer, I. 2007. Doen die Woordeboek van die Afrikaanse Taal XII dit vir die Afrikaanse taal en die Suid-Afrikaanse leksikografie? Lexikos 17: 259-277.

Feinauer, I. 2009. Rondetafelgesprek op 4 Februarie 2009 met prof. I. Feinauer en die WAT-redaksie as gespreksgenote na aanleiding van haar resensie van WAT XII in Lexikos 17: 259-277.

Gouws, R.H. 1985. Die sewende deel van die Woordeboek van die Afrikaanse Taal. Standpunte 38(4): 13-25.

Gouws, R.H. 1989. Leksikografie. Kaapstad: Academica.

Gouws, R.H. 1992. Woordeboek van die Afrikaanse Taal, Deel VIII. SAUK, Skrywers en Boeke.

Gouws, R.H. 1994. Woordeboek van die Afrikaanse Taal, Deel IX. SAUK, Skrywers en Boeke.

Gouws, R.H. 1996. Woordeboek van die Afrikaanse Taal, Deel X. SAUK, Skrywers en Boeke.

Raidt, E.H. 1993. Die agste deel van die Woordeboek van die Afrikaanse Taal. Lexikos 3: 215-226.

Schoonees, P.C. 1952. Bespreking van die Afrikaanse Woordeboek (A-C): Repliek van Hoofredakteur. Tydskrif vir Wetenskap en Kuns Nuwe Reeks 12(2): 289-290.

Schoonees, P.C. 1957. Op los skroewe. Standpunte 11(5-6). 1957: 122-126.

Schoonees, P.C. 1958. Rondom die Woordeboek. Kaapstad: Nasionale Boekhandel Bpk.

Snijman, F.J. 1977. Aangehaal in die berig "Word die WAT dalk eers in 2120 voltooi?", Die Burger, 1 November: 17.

Snijman, F.J. 1995. Die leksikograaf as eksegeet. Opstelle en lesings. Stellenbosch: Buro van die WAT.

Snijman, F.J. 1995a. Bespreking van WAT VI deur J. Combrink - 'n paar opmerkings. Snijman, F.J. 1995: 201-211.

Snijman, F.J. 1995b. Ponering sonder voldoende fundering. Snijman, F.J. 1995: 189-200.

Snijman, F.J. 1995c. Is illustrasies in 'n woordeboek funksioneel? Snijman, F.J. 1995: 157-168.

Snijman, F.J. 1995d. Oor die ensiklopediese. Snijman, F.J. 1995: 169-186.

Swanepoel, P.H. 1995. 'n Eksegese van 'n leksikografiese metode: Die WAT en die probleem van ensiklopedisiteit in die verklarende linguistiese woordeboek. Lexikos 5: 187-210.

Tarp, S. 2000. Theoretical Challenges to Practical Specialised Lexicography. Lexikos 10: 189-208.

Wiegand, H.E. 1984. On the Structure and Contents of a General Theory of Lexicography. Hartmann, R.K.K. (Red.). 1984. LEXeter '83 Proceedings. Papers from the International Conference on Lexicography at Exeter, 9-12 September 1983: 13-30. Tübingen: Max Niemeyer.

Wiegand, H.E. 1994. Elements of a Theory Toward a So-called Lexicographic Definition. Wiegand, H.E. 1999. Semantics and Lexicography. Selected Studies (1976-1996): 203-282. Redaksioneel versorg deur Antje Immken en Werner Wolski. Tübingen: Max Niemeyer.

Zgusta, L. 1971. Manual of Lexicography. Den Haag: Mouton. 